\title{
The Rise and Fall of Animal Behavior Labs: The Future of Comparative Psychology
}

\author{
Terry L. Maple ${ }^{1,2}$ \\ ${ }^{1}$ Elizabeth S. Watts Professor Emeritus, Georgia Institute of Technology, Atlanta, GA \\ ${ }^{2}$ Professor in Residence, Jacksonville Zoo \& Gardens, Jacksonville, FL \\ *Corresponding author (Email: terrylmaple@msn.com)
}

Citation - Maple, T. L. (2016). The rise and fall of animal behavior labs: The future of comparative psychology. Animal Behavior and Cognition, 3(3), 131-134. doi: 10.12966/abc.02.08.2016

\begin{abstract}
Comparative psychology is experiencing a decline in academia. The retirements and losses of its leaders, like Dr. Stan Kuczaj, along with reduced support by the national government and the universities, and pressure by animal activists are some of the reasons for this decline. Students are still interested in the world of animal behavior, but as external pressure increases to focus on applied translational questions and less on basic research, pursuing this topic becomes increasingly difficult. The future of the field rests upon the legacies of leaders, such as Stan Kuczaj.
\end{abstract}

Keywords - Animal behavior, Comparative psychology, Stan Kuczaj

Stan Kuczaj and I were contemporaries who entered graduate school about the same time in the early 1970's. While we were students, three iconic ethologists, Konrad Lorenz, Nikolaas Tinbergen, and Karl von Frisch were awarded the Nobel Prize for Physiology and Medicine. This was long overdue recognition that behavior was just as important as the anatomical and physiological characteristics of living organisms. The Nobel Committee recognized the significance of the "organization and elicitation of individual and social behavior patterns" of birds, fish, and insects. Species differences were interpreted by ethologists as the result of natural selection and extended to mammalian taxa including Homo sapiens. This unexpected achievement was a morale booster for all students of animal behavior and made us feel optimistic about the field we had chosen to study.

In those days, aspiring animal behaviorists had many schools to choose from. The subject was often available in both biology and psychology departments at major universities. At the University of California at Davis, no less than eight faculty members were qualified to supervise my dissertation in the psychobiology program. After completing a post-doc in the Medical School at Davis, I joined the faculty at Emory University. Stan's first job took him to Southern Methodist University (SMU) in Dallas.

As a primate psychobiologist, I had the opportunity to study the largest collection of great apes in the world in the research collection housed at the Yerkes National Primate Research Center. Stan began his work on human language but soon extended his research into the phylogenetic origins of communication in studies of marine mammals. This work reached its apex when he moved from SMU to the University of Southern Mississippi where he founded the Marine Mammal Behavior and Cognition Laboratory.

Over the years, I received many inquiries from student candidates who were seeking an opportunity to enter graduate school. Some of them were admitted to work with me at Georgia Tech. My advice to all of them was to look for a person who was doing what you want to do and then see if they were taking students that year. I was struck that there were so few places that offered the research 
opportunities that worked so well in Atlanta. As animal behavior opportunities dwindled, I was impressed that Stan Kuczaj's lab seemed to be vital and open for business. Both of us prospered as scholars because we attracted a continuous cadre of highly qualified and motivated students. Academia cannot replace an iconic figure like Stan Kuczaj, but one can hope that the university that employed him will retain his laboratory, or something like it, under new leadership. Stan's academic formula worked. It should be continued.

We both knew that we had struck a goldmine of opportunity represented by our fortuitous access to rare populations of sentient beings. We also understood that we would need to go beyond the laboratory to completely understand the nature of these complex and charismatic creatures. In reviewing Stan's life, I believe he would accept the conclusion that he and I operated labs that were each a compelling locus for animal behavior research. This is evident because so many students looked to Hattiesburg and Atlanta as ideal academic settings for observing and understanding the behavior of wild animals. In my career as a university professor, beginning in 1975, I supervised a total of 31 doctoral dissertations. Stan produced more than 50 master's and doctoral students. These brilliant young people were the reason that our research groups could publish so many papers and reach out to so many distant constituencies worldwide. His students have acknowledged with affection his enduring value as a mentor and friend in the pages preceding this tribute. More importantly, he opened doors of opportunity for each and every one of them.

All of our students collectively represent a new generation of experts in animal behavior and comparative cognition. We were both proud of their achievements and expected even greater achievements from them in the future. When I retired in 2008, my department inexplicably decided to end the animal behavior graduate program at Georgia Tech. This resulted in the School of Psychology's loss of the only endowed chair in its history when administrators elected to move the chair to the School of Biology. After fifty years of continuous animal behavior research initiated by my predecessor Richard K. Davenport and continued on my watch, students can no longer earn a Ph.D. in animal behavior at Georgia Tech. Graduate specialties come and go in universities, but highly successful, well-funded programs deserve a better fate.

Stan Kuczaj's passing, and the passing or retirement of any prominent comparative psychologist or ethologist is a moment of concern for all of us who believe animal behavior laboratories, like many of the species we study, are at risk of imminent extinction. Stan's legacy is best preserved and remembered if USM attempts to fill the void of his passing by hiring someone like him. If there is any reason to believe this will not happen, alumni of the program should work together to influence the administrators who will make this important decision. The prominence and the productivity of his lab suggests that it should be continued by a colleague who is well respected by Stan's academic peers. USM's Brain and Behavior graduate curriculum is well positioned to support a continuation of students involved in animal behavior and cognitive research. It may be, however, that his popularity will work against his interests. Academic leaders chase government research funding, and animal research is often sustained by private contributions from donors and foundations concerned about the fate of the creatures we study. I wrote about this issue in a paper published in the Observer (Maple, 2006). Sadly, it is not uncommon for universities to try to shift the focus of an endowment even when there are qualified people to keep it going. We should protect the interests of the donor and the scholar. Our work is more successful when it is part of a long-term commitment.

\section{Stan's Contributions to Animal Welfare}

All of us who work with big-brained mega-fauna feel empathy for their vulnerability in the wild and regret any role we've played in confining them to learn about them. Our own work has resulted in upgraded facilities in zoos, aquatic parks, and research laboratories, improving their psychological wellbeing while providing sufficient space for assembling larger groups. Psychologists may have been blamed for the limits of captivity, but they have also worked at the forefront of innovation and reform. Stan Kuczaj's publications (e.g., Kuczaj, Winship, \& Eskelinen, 2015) documented the discovery of novel 
behaviors in belugas (Delphinapterus leucas) and bottlenose dolphins (Tursiops truncatus), and his awareness of their needs enlightened those who operated aquatic facilities. Other contributions quantified the temporal distribution of behavior in zoo elephants (Loxodonta africana) (Horback, Miller, Andrew, \& Kuczaj, 2014). His ideas and innovations will be remembered as his many students make their mark and contribute to the discussion about cetaceans in human care (see Hill, Guarino, Dietrich, \& St Leger, 2016, this issue).

\section{The Mysteries of Animal Behavior}

At no time in my career has the public been more interested in the mental and emotional life of animals. Yet, animal psychological science is becoming harder to find in the curriculum of our colleges and universities. The narrow focus on human behavior cannot succeed without the context represented in the vast biodiversity of animal behavior. Our students understand this and they show great interest whenever a course in animal behavior and cognition is offered.

In a recent paper published in The Behavior Analyst (TBA), my coauthor and I (Maple \& Segura, 2014) reviewed the systematic disappearance of animal labs associated with the field of applied behavior analysis. In fact, in most ABA programs today, students with little or no laboratory animal experience are being trained to work exclusively with developmentally disabled or autistic human populations. If there are no animal labs, there can be no opportunities to learn behavioral principles with animals. Too many of today's students must learn about the history of experimental psychology without ever observing a rat, pigeon, or any other laboratory animal. A growing number of applied psychologists are concerned by this dismal trend. In an important review by Abramson (2015), the author found only 12 percent of colleges and universities in a population of 650 institutions offered a course in comparative psychology. As we have learned, however, there is plenty of student enthusiasm for animal courses that include cetaceans and nonhuman primate subjects but not so many professors who are able to gain access to these populations. Stan Kuczaj made comparative psychology relevant and a lot of fun.

The great value of animal studies is also demonstrated in a new book (Marston \& Maple, 2016) that documents comparative psychology's important contributions to clinical psychology and psychotherapy. This book is getting traction and at least one symposium is in the works, a result of the synergy spawned by thoughtful consideration of these historic connections.

In the pages of TBA, other contributors (Friman, 2010; Normand \& Kohn, 2013; Poling, 2010) have acknowledged that $\mathrm{ABA}$ will not be a healthy field unless it broadens the base of its science and practice to include new working venues. One promising direction for ABA is to focus its attention on animals in service to humanity in zoos, aquariums, marine parks, biomedicine, and agriculture. There is no question that $\mathrm{ABA}$ is an important epistemology that benefits animals in these settings. We need to return the study of animals to the broad purview of this field. If psychologists can no longer work with animals, the public's interest in them will be distorted by misinformation and the silly proclamations of psychological charlatans. As wild animals continue to suffer in the natural world, scholars who specialize in animal behavior will be needed to address their plight and provide data to understand and protect them.

History has conspired to bring hard times to animal psychological science. Labs have closed due to zeitgeist shifts from behaviorism to cognitive psychology, while animal rights groups have made it difficult to maintain animal facilities on campus. Leading wildlife experts have weighed in to influence the closing of the federal government's investment in primate research. Unfortunately, when behavioral scientists leave the scene, the institutions that remain are devoid of a conscience; they lose their connection to the whole organism when there are no anthropologists, ethologists, or comparative psychologists to advocate for a holistic perspective. As a result, biomedicine as a whole is more vulnerable to criticism from those who see only the exploitation of unwilling subjects. By our absence, universities are no longer the experts on animals. It is now the privately funded animal rights groups that will speak for animals, and they won't get it right. Creative thinkers like Stan Kuczaj are needed in the field of psychology. Thankfully, Stan left a legacy of young collaborators. They will be useful if we can find a place for them in our colleges and universities. 


\section{Scholar, Editor, Mentor, Leader}

Stan Kuczaj was a true renaissance man. He was a prolific scholar who published with his students and shared the credit for his brilliant ideas. By working so closely with them in publishing and presenting original research he was doing what good mentors do. He was also confident enough to found and lead scientific journals, such as Animal Behavior and Cognition. By these decisive acts he was unleashing creative opportunities for other scholars to share their ideas. Stan brought people together to advance their interests. He also led departments, no easy task, and managed the productivity of units that likely needed his careful guidance. In a simple phrase, Stan Kuczaj was a builder who enabled others to succeed.

Animal behaviorists are trained to observe beings of a different kind. It is not surprising that other behavioral scientists are willing to be led by someone with keen observational skills honed in an arena that requires patience and insight. In addition to these objective abilities, Stan had the temperament and the personality to joyfully lead others. This is a rare skill and one reason why so many people thrived in his domain. There is a reason that Stan Kuczaj was so famous. He was the right person to introduce a new generation to the importance of biodiversity and the individuals that were capable of thinking and feeling just like the human beings who were so fascinated by them. It may take many years before we encounter someone as capable and creative as Stan Kuczaj. Until then, we must be content to remember him and emulate his unique approach to his life and his career. He was a splendid example for a universe of students and colleagues. The academy is substantially diminished by his loss.

\section{References}

Abramson, C. I. (2015). A crisis in comparative psychology: Where have all the undergraduates gone? Frontiers in Psychology, 6, 1500. doi: 10.3389/fpsyg.2015.01500

Friman, P. C. (2010). Come on in, the water is fine; Achieving mainstream relevance through integration with primary care. The Behavior Analyst, 33, 19-36.

Hill, H. M., Guarino, S., Dietrich, S., \& St. Leger, J. (2016). An inventory of peer-reviewed articles on killer whales (Orcinus orca) with a comparison to bottlenose dolphins (Tursiops truncatus). Animal Behavior and Cognition, 3(3), 131-145. doi: 10.12966/abc.03.08.2016

Horback, K. M., Miller, L. J., Andrew, J., \& Kuczaj, S. A. II. (2014). Diurnal and nocturnal nighttime activity budgets of zoo elephants in an outdoor facility. Zoo Biology, 33, 403-410. doi: 10.1002/zoo.21160

Kuczaj, S. A. II, Winship, K. A., \& Eskelinen, H. C. (2015). Can bottlenose dolphins cooperate when solving a novel task? Animal Cognition, 18(2), 543-550. doi: 10.12966/abc.02.07.2015

Maple, T. L. (2006). Tales of an entrepreneurial animal psychologist. APS Observer, 19, 11-13.

Maple, T. L., \& Segura, V. (2015). Advancing behavior analysis in zoos and aquariums. The Behavior Analyst, 38, 77-91.

Marston, D., \& Maple, T. L. (2016). Comparative psychology for clinical psychologists and therapists. London, UK: Jessica Kingsley Publishers.

Normand, M. P., \& Kohn, C. S. (2013). Don't wag the dog; Extending the reach of applied behavior analysis. The Behavior Analyst, 36, 109-122.

Poling, A. (2010). Looking to the future: Will behavior analysis survive and prosper? Journal of Applied Behavior Analysis, 33, 7-17. 